\title{
Review on Opportunities of Developing Biotechnology in Animal Feed Improvement and Major Constraints Hinder Biotechnology in Developing Countries
}

\author{
Nebi Husein Meseret Girma

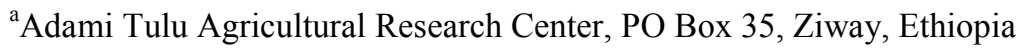 \\ ${ }^{\mathrm{b}}$ School of Animal and Range Sciences, Haramaya University, PO Box 138, Dire Dawa, Ethiopia
}

\begin{abstract}
Biotechnologies have donated enormously to increasing the level of livestock productivity, particularly in developed countries, and can help to alleviate poverty and hunger, increase the availability of feed resources and ensure environmental sustainability in developing countries. It improves availability of feed throughout the year in both quantity and quality by treating locally available feed resources with biotechnology by product(feed additives), improving rumen fermentation of fibrous feed (crop residues) and enhancing the nutritive value, utilization of agro-industrial by-products and other forages. Biotechnology applications improve the performance of animal and animal by product through consumption of improved nutrition. Biotechnology will play an essential role in the economic future of developing countries in maintaining the globally attractive or desirable plant or seed that are adapted to the desired agro ecology by using recombinant DNA technology. The constraints of biotechnology in animal production in developing countries are due to poverty, malnutrition, disease, increasing of field crop production, poor livestock production systems, poor hygiene and unemployment. There is a need to ensure favorable infrastructure, such as repositories of biotechnology resources, biotechnology information centers, good roads and communication channels and a strengthened regional technical cooperation network
\end{abstract}

Keywords:- Animal feed, Biotechnology, Developing country and Feed additives

DOI: $10.7176 / \mathrm{JAAS} / 52-01$

\section{Introduction}

Livestock production is one of the fastest growing agricultural sectors in developing countries, where it accounts for more than a third of agricultural GDP (FAO, 2006). In developing countries, livestock production is increasing rapidly as a result of growth in population, incomes, changes in lifestyles and dietary habits (FAO, 2003). Demand for livestock products in the developing countries is increasing because of the increasing human population, growth in income and urbanization (Hsu et al.; 1991). Most food of animal origin consumed in developing countries is currently supplied by small-scale, often mixed crop-livestock, family farms or by pastoral livestock keepers (Ruane and Zimmermann, 2001). The productivity of animal agriculture in developing countries will need to be substantially increased in order to satisfy increasing consumer demand, to more efficiently utilize scarce resources and to generate income for a growing agricultural population. Biotechnology has the potential to improve the productivity of animals via increasing in growth, carcass quality and reproduction, improved nutritional quality, safety of food, improved health and welfare of animals and reduced waste through more efficient utilization (Madan, 2005).

Biotechnology provides possible solutions to many economic, social, and environmental problems. Agricultural biotechnology has been practiced for a long time, as people have sought to improve agriculturally important organisms by selection and breeding. This includes forage plant breeding to raise and stabilize yields; to improve resistance to pests, diseases and abiotic stresses such as drought and cold; and to enhance the nutritional content of nature pasture and for conservation of animal feed resources. The shortage of feed developing countries and the increasing cost of feed ingredients mean that there is a need to improve feed utilization. Aids to animal nutrition, such as enzymes, probiotics, single-cell proteins and antibiotics in feed, are already widely used in intensive production systems worldwide to improve the nutritive value of availability of feeds resource and the productivity of livestock throughout the years. Therefore, the objectives of this paper were to review the opportunity of application of biotechnologies in improving animal nutrition in developing countries. This paper was design to review on the opportunities of development of biotechnology in animal nutrition

\subsection{Animal Biotechnology}

Biotechnology is a technique that uses living organisms or substances to make or modify a product, to improve plants or animals or to develop micro-organisms for specific purposes (Kayang, 2013). Biotechnology provides possible solutions to many economic, social, and environmental problems that facing developing country. Biotechnology has the potential to provide new opportunities for achieving enhanced livestock productivity in a 
way that alleviates poverty, improves food security and nutrition and promotes sustainable use of natural resources.

Ramli-Bin et al., (2011) defined the term "Animal biotechnology" as the application of scientific and engineering principles to the processing or production of materials from animals or aquatic species to provide goods and services for the well being of human populations. Biotechnology has been practiced since the beginning of animal husbandry (FAO, 2011). Applications of biotechnology in animal production focused on four fields; reproduction, selection and breeding, animal health; feeding and nutrition; growth and production. In the developing countries, the application of animal biotechnology is essential to improve animal production and to conserve the indigenous animal genetic resources. Animal reproductive biotechnologies will be useful in implementing embryo transfer and related technologies, diagnosing diseases and controlling and improving the animal feed resource quality.

\subsection{Biotechnology in Animal nutrition}

In animal nutrition, biotechnology can improve the plane of nutrition through the protection of protein, amino acids (Yadav and Chaudhary, 2010) and fat (Shelke et al., 2011). Most African livestock production is under traditional systems in which feeding and nutrition are depending on climatic factors. Feed availability and quality closely following the rainfall patterns. During the dry season, there is inadequate feed and the nutritive quality of whatever is available is generally too poor to support animal maintenance, much less production; a common problem is low protein and high fiber content. There are a number of biotechnologies which use microorganisms to improving nutritional quality, including digestibility of low quality feed, reduce the wastage feed, protect the animals from diseases, remove anti-nutritive and increase acceptability of using enzymes, probiotics, antibiotics and gene-based technologies (modifying feed to be more digestible) ( Kayang, 2013).

\subsection{Status of Animal Feed in Developing Country}

Inadequate feed supply mainly due to small land-size and overstocking due to the shrinking amount of land reserved for grazing. The low feeding value of available feed resources which is used for fulfill maintenance requirements with little surplus for production. Fibrous feeds with poor digestibility and low intake result in low levels of production. Crop residues and agro-industrial by-products are largely wasted or inefficiently used because the infrastructure for transporting, processing and marketing. Available feeds resource during dry periods is very poor quality (low in protein and high in fiber), low digestibility and low voluntary intake, crude protein content is below 7\% is inadequate for proper rumen function, poor availability and access to water. During rainy season low dry matter intake from grazed forages due to high moisture content of vegetation and high wastage or deterioration of valuable feed resources (Gatenby, 2002).

\subsection{Contribution of Biotechnology in Animal Feed Improvements}

Animal feed represents one of the most serious limitations of livestock production in developing countries, especially in the tropics. Biotechnological options are the open for improving availability of feed throughout the year in both quantity and quality by conserving locally available feed resources treating with biotechnology by product, improving rumen fermentation of fibrous feed (crop residues) and enhancing the nutritive value, utilization of agro-industrial by-products and other forages. Biotechnology application is being for improving the performance of animal through better nutrition production. Enzymes can improve nutrient availability from feed stuff, lower feed cost and reduce the output of waste into the environment. Prebiotics and probiotics or immune supplementation can inhibit pathogenic gut microorganism or make the animal more resist to them.

\subsubsection{Biotechnology for Fibrous Feeds and Rumen Function Improvement}

Low-quality forages are a major component of ruminant diets in the tropics. Fibrous feeds has a low digestibility, low intake and low in palatability, comprise the major proportion of feeds accessible to most ruminants under smallholder situations in developing countries (Lebbie and Kagwini, 1996). It is well known that some microorganisms, including cellulose enzymes from anaerobic bacteria and white rot fungi can degrade lignin in the cell walls (treatment of roughages). Several fungal strains have been used for lingo cellulosic hydrolysis such as Asprigullus niger, A. terreus, Fusarium moniliforme and Chaetomium celluloyticum. At present, the main treatment methods for forages such as cereal straws are either mechanical (grinding), or a range of chemical treatments of which sodium hydroxide or ammonia are among the more successful (Greenhalgh, 1984).

1.5.1. Urea Straw Treatment Technology (UTS)

UTS are better suited for medium-sized or large animal holdings. The biotechnology in these techniques will make little contribution to alleviating poverty among smallholders. Treatment of crop residues with ammonia using fertilizer grade urea has received much attention, especially in Asia. Urea-ammonia treatment of straw is a technically effective and feasible on-farm technology to improve the nutritive value of fibrous crop residues. The feeding of UTS alone will lead to some increase in production, but the full potential will only be realized when the correct supplements are added (Sharma et al., 2004) 
1.5.2. Urea Molasses Block Technology (UMB)

UMB is a high protein concentrated feed containing necessary amount of minerals and vitamins. It supplies Non protein Nitrogen (NPN) to the rumen microbes without any risk. It contains nitrogen and energy for rumen micro- organisms. NPN is containing sufficient product which can be used as a nitrogen source while molasses used as supplementary energy source. The nitrogen from urea is used by the rumen microbes to make microbial protein. UMB contains important ingredients like, urea, noug cake, molasses, mineral mix, wheat bran and salt. It was proved to be complete balanced diet for the animals. It enhances the intake of the animal's especially roughage feeds (Banerjee, 1982).

1.5.3. Improve Nutritive Value of Conserved Feed

Feed conservation include fermentation silage-making. The conservation of plant material as silage depends upon anaerobic fermentation of sugars in the material which in turn is influenced by the ability of naturally occurring lactic acid bacteria to grow rapidly on the available nutrients under the existing physical environment. The ensiled material is sterilized by lactic acid bacteria. In addition to the number and type of bacteria, other interrelated factors may affect quality of silage, including availability of water-soluble carbohydrates, the drymatter content, the $\mathrm{pH}$ and extent of air exclusion. For example, lack of water-soluble carbohydrates may be overcome by wilting the material to raise the dry matter to a level at which less acid is required to stabilize the fermentation. The availability of sugars in the material and the rate at which the different micro-organisms multiply also influences the ensilage process.

A group of compounds classified as fermentation stimulants have been widely studied. These include sugar sources (example molasses and whey), enzymes and lactic acid bacteria. Molasses is one of the particular relevance to smallholder farmers in developing countries in the tropics where sugar-cane is produced and processed. Enzymes are essential for the breakdown of cell-wall carbohydrates to release the sugars necessary for the growth of the lactic acid bacteria. Although resident plant-enzymes and acid hydrolysis produce simple sugars from these carbohydrates, addition of enzymes derived from certain bacteria likes, Aspergillus niger or Trichoderma viridi (Henderson et al., 1982) increases the amount of available sugars. Commercial hemicellulase and cellulase enzyme cocktails are now available and improve the fermentation process considerably (Hooper et al., 1989). The objective of using additives is to ensure the rapid production of the required amount of lactic acid from the carbohydrates present to preserve the ensiled material.

1.5.4. Improve Nutritive value of Cereals

Moderate protein content and low amounts of specific amino acids limit the nutritive value of cereals and cereal by-products (examples, barley is low in Iysine and threonine). This is a major limitation in the ration formulation for non-ruminant livestock which necessitates addition of expensive protein supplements. There are on-going studies to enhance the low level of Iysine in barley by genetically engineering the grain genome through Genetic modification through insertion of genes (Miflin et al., 1985; Shewry and Kreis, 1987).

1. 5.5. Improve Rumen Function

Rumino-reticulum is the main digesting environment in ruminating animals and both microbial and animal's own enzymes and chemicals work together to digest feeds and synthesize new nutrients and other substances. In rumen there are several types of microorganisms actively involved in the digestion of fibrous, starchy, protein parts of the feeds and anti-nutritive substances. Basically, four groups of microorganisms occupy the rumen, including bacteria, methanogens, protozoa, and fungi (Nagaraja, 2012). However, microbes and, therefore, rumen environment have limited capacity to digest cellulose substances compared to other polysaccharides such as starch or proteins. Therefore, manipulating rumen microorganisms and the relative population of certain species might help to increase the digestibility of high woody plants or low quality feeds.

Enzyme activity has focused on three areas: first, the relative increase in the population of certain bacteria depending on the ingested materials, second determining the genes responsible for synthesizing those enzymes and manipulating them, and third, the addition of exogenous enzymes before the material is ingested. These are from enzymes, direct fed microbial (DFM), or probiotics, prebiotics, and some plant extracts (Beauchemin et al., 2006; Nagaraja, 2012). Other method of manipulating the rumen environment was to add live microorganisms to the rumen, especially using aspergillus and saccharomyces, which resulted in a benefit for production (Gaggia et al., 2010). The effect of this enzymes or microbial are improved the major performance parameters (dry matter intake, fiber digestion, average daily gain, and feed efficiency) in beef cattle (Beauchemin et al., 2006)

1.5.6. Remove Anti-nutritive Factors

Anti-nutritive factors in plant tissues include protease inhibitors, tannins, phytohaemagglutinins and cyanogens in legumes, and glucosinolates, tannins and sanapine in oilseed rape (Brassica napus) and other compounds in feeds belonging to the Brassica group. As with amino acid deficiencies, the adverse effects of these compounds are more marked in non-ruminants than in ruminants (Chubb, 1983). Conventional plant breeding has been used to reduce and, in some cases, eliminate such anti-nutritive factors. An example is the introduction of cultivars of oilseed rape which are low in, or free from erucic acid and glucosinolates. A combination of genetic engineering and conventional plant breeding should lead to substantial reduction or removal of the major anti-nutritive 
factors in plant species of importance as animal feeds. Transgenic rumen microbes could also play a role in the detoxification of plant poisons (Gregg 1989) or inactivation of anti-nutritional factors. Successful introduction of a caprine rumen inoculum obtained in Hawaii into the bovine rumen in Australia to detoxify 3-hydroxy 4(IH) pyridine (3,4 DHP), a breakdown product of the non-protein amino acid mimosine found in Leucaena forage (Jones and Megarrity, 1986).

\subsubsection{Biotechnologies in Forage Breeding}

Biotechnology will play an essential role in the economic future of developing countries in maintaining the global attractiveness of forage- production. The genomics era has added a new dimension to cultivar development, with marker-assisted selection, allowing more precise genome modifications during plant breeding, and plant transformation providing more direct and novel routes for cultivar improvement. Genetically engineered forage crops are genetically modified using recombinant DNA technology with the objective of introducing or enhancing a desirable characteristic in the plant or seed that are adapted to the desired agro ecology (Spangenberg et al., 2001). It is known that forage legumes are comparatively low in sulfur-containing amino acids and their availability to ruminants is further adversely affected during rumen digestion. This leads to the reduction of the optimum for the animal growth level of essential amino acids.

Plant genetic modification with genes encoding for a sulfur amino acid-rich proteins, resistant to rapid rumen degradation can compensate this deficiency. Agronomic researchers around the globe are currently using recombinant DNA technology to create new and altered species of plants. In another study, researchers at the noble foundation have been successful in manipulating lignin composition and levels in alfalfa and other forages to improve their digestibility and the conversion of biomass to biofuels. Some shrubs and trees respond to leaf damage as occurs by grazing and produce greater quantities of secondary compounds which often make them inedible.

Genetics and plant breeding have made a huge contribution toward forage crop performance in pasturebased systems, and biotechnology will provide future innovations and opportunities. For this approach researchers will need to fully integrate functional genomics with genetics, biochemistry, plant biology, agronomy and farm system management of forage. These tools provide an exciting opportunity to tackle some of the challenges faced in optimizing pasture or forage based farming systems (Gergory, 2001).

The main limiting nutrient in animal feeds is protein (Rufino et al., 2006) and recent developments in optimizing the use of legumes, shrubs and trees for feedstock and propagating them in all agro-ecological zones ranging from arid to wet areas would alleviate this constraint. The scarcity and poor quality of forages used as energy sources in the dry seasons is an additional constraint. Improvements in microbial genomics and biotechnology have made it possible to increase the areas and feed resources available to ruminant animals through improvements in utilization of forages (Makkar and Viljoen, 2005).

\subsubsection{Biotechnology Products as Feed Additives}

Biotechnology has been a significant contributor for the development of additives which improve efficiency animal production in both intensive and extensive. Feed additives include antibiotic, enzymes, probiotics and prebiotics (McDonald et al., 2010). Industrial fermentation is the intentional use of fermentation by microorganisms, such as bacteria and fungi, to make products useful for animals. Fermented products or those derived from fermentation have several applications in animal feeding. Amino acids and enzymes are well known as fermentation products; both are crucial for optimization of livestock performance. However, fermentation can also be used to upgrade raw materials. Improve digestibility and in addition, biologically active compounds are often formed, which may have a positive impact on the health status of animals (Niba et al., 2009). The range of additives used in the animal production industry is very broad, ranging from vitamins, trace minerals, growth promoters, and disease preventing agents and have played a role in improving palatability, physical characteristics and preventing rancidity of the feed.

\subsubsection{Antibiotics}

Antibiotics are antimicrobial pharmaceutical, usually of plant or fungal origin and are also synthesized in laboratory. The primary use of antibiotics is in the treatment of infections, reduce the number of pathogenic bacteria (Escherichia coli, Salmonella species), prevent the infection of the digestive tract, reduce the competition of bacteria with the host (bacteria ferment the nutrients before digestion) and a certain antibiotics are used as feed additives in order to improve growth and feed conversion efficiency (McDonald et al., 2010). Monensin is an antimicrobial compound that is produced in large amounts by Streptomyces cinnamonensis. In 1971 , monensin was originally introduced into the poultry industry as an anti coccidial agent. Some countries have approved its use in the diets of swine and ruminant animals, particularly dairy cows and beef cattle. But it is prohibited for use during lactation in dairy cows and laying chickens (MOA, 2001).

1.5.3.2. Amino Acids

Amino acids in feed, lysine, threonine, tryptophan and methionine constitute the largest share of the total amino acid. Amino acids are mostly produced by microbial fermentation and in the world market for fermentation products, after ethanol and antibiotics, amino acids are the most important category and demand for them is 
increasing rapidly. Most grain-based livestock feeds are deficient in essential amino acids such as lysine, methionine and tryptophan and for high producing mono gastric animals (pigs and poultry) these amino acids are added to diets to increase productivity. Balancing of diets using amino acids also decreases excretion of nitrogen from the animals into the environment (Leuchtenberger et al., 2005).

1.5.3.3. Enzymes

Enzymes are proteinaceous biocatalysts, generally of microbial origin, that improve feed nutrient availability by enhancing the digestibility of macromolecules and decreasing anti-nutritional factors. An additional advantage is a potential decrease in environmental pollutants from livestock production systems. Some examples are phytase, glucanase and xylanase (Selle and Ravindran, 2007). Phytases are microbial strains that are either derived through mutation or by using recombinant DNA technology (by recombinant strains of Aspergillus niger, A. oryzae and Trichoderma reesei).

Phytase addition can reduce phosphorus excretion by up to $50 \%$, contributing significantly to environmental protection. It also increases profitability (phosphorus resources are limited and expensive) by decreasing the amount of phosphorus added to the diet and increasing productivity by improving the availability of minerals, trace elements and nutrients for the animal. Their main purpose is to improve the nutritive value of diets, especially when poor-quality, and usually less expensive, ingredients are incorporated. In livestock nutrition, enzymes improve the availability of plant storage polysaccharides (example starch), oils and proteins, which are protected from digestive enzymes by the impermeable cell wall structures. Enzymes are essential for the breakdown of cell-wall carbohydrates to release the sugars necessary for the growth of the lactic acid bacteria (Rode et al., 2001).

1.5.3.4. Probiotics and Prebiotics

Probiotics are live microbial feed supplements which beneficially affect the host animal by improving the intestinal microbial balance (Mada, 2005). They supplement immune to inhibit the entrance of bacteria. These are usually from the Lactobacillus and Bifidobacterium families for monogastric animals, while Aspergillus oryzae and Saccharomyces cerevisiae are generally used for ruminants. The most common probiotics are lactic acid producing bacteria reducing the $\mathrm{pH}$ in the intestine, reducing the numbers of harmful bacteria and improve rumen efficiency. They are feed supplements that are added to the diet of farm animals to improve intestinal microbial balance (Fuller, 1989). It prevents mimosine toxicity and enables the safe use of Leucaena leucocephala as a protein-rich feed in many developing countries. These microorganisms are responsible for production of vitamins of the B complex and digestive enzymes, and for stimulation of intestinal mucosa immunity, increasing protection against toxins produced by pathogenic microorganisms. The most common prebiotics are oligosaccharides, which are non-digestible carbohydrates.

\section{Major Constraints on Applying Biotechnology in Developing country}

The constraints of biotechnology in animal production in developing countries are due to poverty, malnutrition, disease, increasing of field crop production, poor livestock production systems, poor hygiene and unemployment. The major constraints have been specifically listed out by Madan (2003), which include: lack of database on livestock and animal owners in most of the developing world, lack of trained scientists, technicians and fieldworkers, absence of mechanism between industry, universities and institutions for technology transfer, expensive technology to be purchased from the developed world, and high cost of technological inputs

\subsection{Poverty}

According to the World Bank (1996) between 45\% and 50\% of Africa's population is poor and live in abject poverty. The poor status is a result of limited employment opportunities, inadequate access to develop biotechnology, low endowment of human capital, environmental degradation and decades of economic mismanagement, corruption, improper governance and conflicts. The GDP of sub- Saharan Africa remains lower than that of other regions of the world. They do not focus their attention on technologies that are relevant to the poor populations in developing countries because these populations cannot afford them. This denies the poor smallholder farmer the chance to access improved biotechnologies for increased production.

\subsection{Infrastructural Development}

Infrastructure denotes the materials, institutional, personal facilities and arrangements that facilitate production and movement of goods and services (Karugia et al. 2003). They include roads, storage facilities, research facilities and market centers. Developing country lacks effective research facilities that are compatible with progress in biotechnology, example there are few specialized laboratories where research can be adapted to meet local conditions. In fact, it is argued that only the International Livestock Research Institute (ILRI) is able to undertake livestock biotechnology research in sub-Saharan Africa despite the fact that it cannot manage to address all problems facing the livestock sub-sector in the region. 


\subsection{Ineffective Marketing Systems}

Agricultural markets in Africa have for a long time been under the control of central governments with limited involvement of private sector players. This meant supplying of inputs, market information and marketing of produce by state managed and controlled cooperative societies. Central governments were also responsible for maintaining services that ensured effective delivery, example transport services. Increasing efficiency in the marketing channels, malfunctioning input supply, output marketing systems and inadequate market information resulted due to lack of adequate infrastructure and government support. Costs of inputs increased while product prices went down due to the long chains of marketing transactions involved.

African countries continue to face external influences from the developed world in of trade policies and barriers that negatively affect access to technologies, production and markets for products. First, the global market for biotechnologies is under the control of a few private-sector investors due to mergers and acquisitions. For commercial reasons, these few biotechnology investors target the rich farmer as the main market while giving less consideration to the poor small-scale farmer. Secondly, the subsidization policies in developed nations (for production and exporting) offset the real market prices making products from unsubsidized smallholder farms more expensive and unprofitable (Johnson, et al., 2003). Thirdly, most products from the region are sold as bulk raw materials with minimal or no value addition. Moreover, any value addition subjects them to escalating tariffs in developed countries (Johnson, et al., 2003) which discourage costly and intensive production that relies on advanced innovations.

\subsection{Research Priorities}

Due to weak economies, most African states emphasize short- and medium-term research to meet the immediate needs of their populations and industry, such as food security and raw materials. Biotechnology requires longterm research to allow time for concrete solutions to biosafety and trade issues and is capital intensive; many nations have not developed/ initiated effective biotechnology research programs. This works against the timely availability of biotechnologies to farmers. There is need for developing countries to commit resources and orient towards long-term research to effectively encompass biotechnology research in their programs as a measure of accelerating the availability of livestock feed resource biotechnologies to smallholder farmers.

\subsection{Extension Systems}

Extension services are meant to offer advice, help farmer's analysis problems, develop opportunities, share information, support formation of groups and facilitate collective action. Extension also allows demonstrations that inform farmers on the best levels of inputs and practices to adopt, especially in the initial stages of technology introduction (Akele et al., 2000) and provides specialists and researchers with valuable information on farmers' needs and efficiency of developed technologies (Damalas, 2003). Many African countries and research institutions have traditionally relied on agricultural extension systems to advance their finding to farmers. However, the extension services are no longer effective because most agricultural extension services have virtually collapsed in much of Africa or have been debilitated by structural adjustments and policy reforms. They have experienced operational lapses and lack of follow-up because of low budgetary allocation by national governments. Both the policy makers and researchers have ignored the independence of livestock extension services (Morton and Wilson, 2000).

\subsection{Training and Research Policies}

Having a sustainable livestock production sector requires different skills, which include animal nutritionists, breeders, forage/range agronomists, veterinarians, sociologists, economists and animal physiologists. However, in many countries across Africa, there is a shortage of skilled capacity in many disciplines to engage in research, support extension and ensure economically viable relationships with technology developers for the benefit of smallholder farmers. Under such a scenario, biotechnology production is left in the hands of private. In other situations there is lack of adequate funds to support research and establish and/or maintain the necessary research facilities. Effective training-research linkages should be enhanced to ensure the needs of farmers are well matched with research development. Therefore, strengthened linkages between training and research institutions and with extension systems for increasing production and productivity of livestock with improved animals feed.

\section{Conclusion}

Modern biotechnology has the potential to provide new opportunities for achieving enhanced livestock productivity in a way that alleviates poverty, improves food security and nutrition and promotes sustainable use of natural resources. Biotechnology is a support for various fields of agricultural production and processing and offers a range of tools to advance our understanding, management and use of crop and livestock resources for different social and economic benefits of man. Fibrous feeds, including crop residues, of low digestibility constitute the major proportion of feeds available for most ruminants under smallholder situations in developing 
countries. Hence, improving these kinds of feeds pre-ingestion will help in increasing nutrient availability and reducing waste of resources. The use of biotechnology to improve post-ingestion quality of fibrous forages is on the verge of delivering practical benefits to ruminant production system in the tropics. In general, adopting biotechnology has benefits in animal feed improvement and economic returns to the livestock entrepreneurs and small producers.

The other application of biotechnology is to produce genetically modified fodder crops of vast benefits to consumers as well as environment like that of food crops. Another area of nutritional biotechnology is the successful attempt in the use of genetically modified microorganisms to enhance rumen fermentation and thereby increase nutrient availability to the host animal. The ultimate goal of using biotechnology in animal feeds and feeding systems is then to improve the plane of nutrition through the use of biotechnology by product, to improve the availability of from feed and to reduce the wastage of the feed. Though application of biotechnology has various opportunities, it is not easily expanded due to prevailing environmental and social constraints of developing countries in the tropics.

\section{Recommendation}

$>$ Opportunity of developing of biotechnology in developing countries is should be need efforts to effective adoption of this new technology and to devise policies for wealth creation, improve livestock production and productivity through improving feed resource, human capacity development to modern job market and conflict resolution are ensuring increased biotechnology application.

$>$ There is a need to ensure favorable infrastructure, such as repositories of biotechnology resources, biotechnology information centers, biotechnology cooperation service, good roads and communication channels and a strengthened regional technical cooperation network.

$>$ Addressing the plight of farmers in access to inputs, value addition, market information and fair marketing systems, and acting as a cohesive group to negotiate for favorable international trade agreements would be required to promote intensive livestock production through improved biotechnology application in developing country in the future.

\section{References}

Akele, S.E.A, Isirimah, N.U, Brisibe, A.A. and Ortiz, R. 2000. The role of extension services for the successful introduction of new Musa cultivars in southwest Nigeria. Paper presented at the International conference on banana and plantain for Africa, Kampala, Uganda.

Banerjee, G.C.1982.A textbook of Animal husbandry .Oxford and IBH publishing Co. Close W and Menke ,K.H. 1986 .selected tropics in Animal nutrition. DSE.pp.170.

Beauchemin KA, Krehbiel CR, Nwebold CJ (2006) Enzymes, bacterial direct-fed microbials and yeast: principles for use in ruminant nutrition. In: Mosenthin R, Zentek J, Zebrowska T (eds.)Biology of nutrition in growing animals. Elsevier Ltd., London

Chubb L.G. 1983. Anti-nutritive factors in animal feedstuffs. In: Haresign W. (ed), Recent Advances in Animal Nutrition. Butterworths, London, UK. pp. 21-37.

Damalas, C.A. 2003. Managing herbicide resistance: The role of extension services. Agribusiness Perspectives Paper 60. http://www.agrifood.info/perspectives/2003/Damalas.pdf.

FAO .2003. The state of the world's animal genetic resources for food and agriculture. B. Rischkowsky \& D. Pilling, eds. Rome.

FAO .2006. Livestock's long shadow: Environmental issues and options, by H. Steinfeld, P. Gerber, T. Wassenaar, V. Castel, M. Rosales \& C. de Haan. 390 pp. Rome.

FAO. 2011. Biotechnologies for Agricultural Development: Proceedings of the FAO international technical conference on "Agricultural Biotechnologies in Developing Countries

Fuller, R., 1989. Probiotics in man and animals. A review. Journal of Applied Bacteriology, 66, 365-378.

Gaggia F, Mattarelli P, and Biavati B. 2010. Probiotics and prebiotics in animal feeding for safe food production. Int J Food Microbiol 141:S15-S28

Gatenby, R.M. 2002. Sheep. The tropical Agriculturalist Series. McMillan publishers. pp.178.

Gergory. 2001. Proceedings of the New Zealand Grassland Association 63: 235-239.

Greenhalgh J.F.D. 1984. Upgrading crop and agricultural byproducts for animal production. In: Gilchrist F.M.C. and Mackie R.I. (eds), Herbivore Nutrition in the Subtropics and Tropics. The Science Press, Pretoria, South Africa. pp. 167-184.

Gregg K. 1989. Enhancement of microbial detoxification by gene transfer. In: Proceedings of the 7th International Symposium on Ruminant Physiology, Sendai, Japan. Academic Press, San Diego, USA. p. 58.

Henderson A.R., McDonald P. and Anderson D. 1982. The effect of cellulase preparation derived from Trichoderma vivide on the chemical changes during the ensilage of grass, lucerne and clover. Journal of the Science of Food and Agriculture 33:16-20. 
Hooper P.G., Sharp R., Rowlinson P. and Armstrong D.G. 1989. An Assessment of the Potential of a Lactobacilli Inoculant as a Silage Additive. British Society of Animal Production, Winter Meeting, 13-15 March. Paper 63. Scarborough, UK.

Hsu, J.T., Fahey Jr., G.C., Merchen, N.R. and Mackie, R.I. 1991. Effects of Defaunation and Various Nitrogen Supplementation Regimens on Microbial Numbers and Activity in the Rumen of Sheep. Journal of Animal Science, 69, 1279-1289.

Johnson, M., Temu, A. and Hazell, P. 2003. Global environment for African agriculture. Paper presented at the InWEnt, IFPRI, NEPAD, CTA conference on Successes in African Agriculture. Conference Paper 17, Pretoria, South Africa, December 1-3 2003.

Jones R.J. and Megarrity R.G. 1986. Successful transfer of DHP degrading bacteria from Hawaiian goats to Australian ruminants to overcome the toxicity of Leucaena. Australian Veterinary Journal 63:259-262.

Karugia, J., Wambugu, S.K. and Oluoch-Kosura, W. 2003. The role of infrastructure and government policies in determining the efficiency of Kenya's maize marketing system in the post-liberalisation era. A research report submitted to the International Food Policy Research Institute (IFPRI) 2020 Vision Network for East Africa.

Kayang B.B, ( 2013) Recent Advances in the Application of Biotechnology in Animal Nutrition

Lebbie S.H.B. and Kagwini E.1996. Small Ruminant Research and Development in Africa. Proceedings of the Third Biennial Conference of the African Small Ruminant Research Network, UICC, Kampala, Uganda, ILRI (International Livestock Research Institute) Nairobi, Kenya. 326 pp

Leuchtenberger, W., Huthmacher, K. \& Drauz, K . 2005. Biotechnological production of amino acids and derivatives: Current status and prospects

Madan. 2003. Opportunities and constraints for using gene-based technologies in animal agriculture in developing countries and possible role of international donor agencies in promoting R\&D in this field. In: Austria, 6-10 October 2003. Food and Agriculture Organisation/ International Atomic Energy Agency, Vienna, pp. 103-104

Madan, M.L. 2005. Animal biotechnology: Applications and economic implications in developing countries. Rev. Sci. Tech. Off. Int. Epiz., 24(1): 127-139.

Makkar H P S and Viljoen G J (eds). 2005. Applications of gene-based technologies for improving animal production and health in developing countries. Springer, The Netherlands

McDonald P., R. A. Edwards, J. F. D. Greenhalgh, C. A. Morgan, L. A. Sinclair and R. G. Wilkinson. 2010. Animal Nutrition. Pearson

Miflin B.J., Kreis M., Bright S.J.W. and Shewry P.R. 1985. Improving the amino acid content of cereal grains. In: Copping L.G. and Rodgers P. (eds), Biotechnology and its Application to Agriculture. Monograph 32. Lavenham Press, Suffolk, England. pp. 71-78.

MOA. 2001. Feed additive drug use norms. Ministry of Agriculture Bulletin, P.R. China No. 168.

Morton, J. and R.T. Wilson, R.T. 2000. The institutional marginality of livestock production extension: the case of Burkina Faso. Livestock Research for Rural Development 12(1). Natural Resources Institute and Bridges Partners, UK.

Nagaraja TG . 2012. A microbiologist's view on improving nutrient utilization in ruminants. In:23rd annual Florida nutrition symposium proceeding, Gainesville, Florida, pp 135-161

Niba, A.T., Beal, J.D., Kudi, A.C. and Brooks, P.H. 2009. Bacterial fermentation in the gastrointestinal tract of non-ruminants: Influence of fermented feeds and fermentable carbohydrates. Trop. Anim. Health Prod. 41:1393-1407.

Ramli Bin Abdullah, Wan Khadijah Wan Embong and Hui Hui Soh. 2011. Biotechnology in Animal Production in Developing Countries. 2nd International Conference on Agricultural and Animal Science, vol.22, IACSIT Press, Singapore.

Rode, L.M., McAllister, T.A., Beauchemin, K.A., Morgavi, D.P., Nsereko, V.L., Yang, W.Z., Iwaasa, A.D. and Wang, Y. 2001. Enzymes as direct feed additives for ruminants. In R. Renaville \& A. Burny, eds. Biotechnology in animal husbandry, Vol. 5, pp. 301-332.

Ruane, J. and Zimmermann, M. 2001. Report of the First Six E-Mail Conferences of the FAO Electronic Forum on Biotechnology in Food and Agriculture.

Rufino M C, Rowe E C, Delve R J and Giller K E. 2006. Nitrogen cycling efficiencies through resourcepoor African crop-livestock systems. Agriulture, Ecosystems \& Environment

Selle PH and Ravindran V (2007). Microbial phytase in poultry nutrition.

Sharma K, Dutta N and Naulia U., 2004. An on farm appraisal of feeding urea-treated straw to buffaloes during late pregnancy and lactation in a mixed farming system. Livestock Research for Rural Development. Volume16.

Shelke, S.K., S.S, Thakur and A.A. Amrutkar. 2011. Effect of pre partum supplementation of rumen protected fat and protein on the performance of Murrah buffaloes. 
Shewry P.R. and Kreis M. 1987. Biotechnology and improvement of feeds. Proceedings of the Nutrition Society 46:379-385.

Spangenberg G, Kalla R, Lidgett A, Sawbridge T, Ong EK, John U. 2001. Transgenesis and genomics in molecular breeding of forage plants. ttp://www.regional.org.au/au/asa/2001/plenery/6/spangenberg.htm.

Yadav, C.M. and J.L. Chaudhary (2010). Effect of feeding protected protein on the growth performance and physiological reactionin crossbred heifers. 